\title{
Gleason Pattern 2
}

National Cancer Institute

\section{Source}

National Cancer Institute. Gleason Pattern 2. NCI Thesaurus. Code C28086.

A pattern of prostate carcinoma characterized by the presence of glands that are more loosely arranged and less uniform compared to Gleason pattern 1. Minimal invasion of the surrounding parenchyma may be present. The epithelial polarity of the malignant cells is preserved and luminal differentiation is present in all glands. 